\title{
Isolation, screening and identification of mercury resistant bacteria from mercury contaminated soil
}

\author{
Anna Kowalczyk ${ }^{1,4}$, Magdalena Wilińska1, Marek Chyc ${ }^{2,3}$, Monika Bojko1 and Dariusz Latowski1,a \\ ${ }^{1}$ Department of Plant Physiology and Biochemistry, Faculty of Biochemistry, Biophysics and Biotechnology, Jagiellonian \\ University, Gronostajowa 7, 30-387 Kraków, Poland \\ 2Silesian Environmental Doctoral Study, Plac Gwarków 1, 40-166 Katowice, Poland \\ ${ }^{3}$ Department of Environmental Protection, State Higher Vocational School in Tarnów, Mickiewicza 8, 33-100 Tarnów, Poland \\ ${ }^{4}$ Department of Environment Protection, Faculty of Geology, Geophysics and Environment Protection, AGH University \\ of Science and Technology, Mickievicza 30 30-059 Kraków
}

\begin{abstract}
New bacterial strains resistant to high concentration of mercury were obtained and characterized focusing on their potential application in bioremediation. The biological material was isolated from soil contaminated with mercury. The ability to removal of $\mathrm{Hg}$ from the liquid medium and the effect of the various $\mathrm{pH}$ and mercury concentrations in the environment on bacterial strains growth kinetics were tested. The selected strains were identified by analysis of the $16 \mathrm{~S}$ ribosome subunit coding sequences as Pseudomonas syringae. The analys is of $\mathrm{Hg}$ concentration in liquid medium as effect of microbial metabolism demonstrated that $P$. syringae is able to remove almost entire metal from medium after 120 hours of incubation. Obtained results revealed new ability of the isolated strain P. syringae. Analyzed properties of this soil bacteria species able to reduce concentration of $\mathrm{Hg}$ or immobilize this metal are promising for industrial wastewater treatment and bioremediation of the soils polluted especially by mercury lamps scrapping, measuring instruments, dry batteries, detonators or burning fuels made from crude oil, which may also contain mercury. Selected bacteria strains provide efficient and relatively low-cost bioremediation of the areas and waters contaminated with $\mathrm{Hg}$.
\end{abstract}

\section{Introduction}

Nowadays energy industry brings numerous benefits for humans, but on the other hand it also carries the risk of natural environment pollution. One of the most hazardous pollutants associated with energy industry is mercury. Even though this element is natural component of environment and forms variety of species revealing different chemical features and level of toxicity, the progress of energetic technologies causes, that the concentration of $\mathrm{Hg}$ in environment significantly increases $[1,2]$. The main anthropogenic source of $\mathrm{Hg}$ emission to air is fuel combustion both in power plants and in residential or commercial boilers [3].

Burning of fossil fuels releases to the atmosphere more than $800 \mathrm{t} \mathrm{Hg}$ per year and it is thought to be the most important anthropogenic source of this pollutant. Generally, it is thought that annually the global $\mathrm{Hg}$ emission due to fossil fuels burning is between $374 \mathrm{t}$ and $1121 \mathrm{t}$ and more than $90 \%$ of $\mathrm{Hg}$ coming from this kind of fuels is released to the atmosphere as a result of stationary combustion [4]. The content of $\mathrm{Hg}$ in the fuel as well as level of $\mathrm{Hg}$ removal from exhaust gases formed during fuels burning are important factors effecting on $\mathrm{Hg}$ emission while combustion process. Among the fossil fuels main source of $\mathrm{Hg}$ emitted to atmosphere is coal but also combustion of another sorts of fuels like oil, wood or even biofuels connected with power or heat production causes $\mathrm{Hg}$ emission. It is worth to consider that not only stationary combustion, but also mobile sources can cause increase of $\mathrm{Hg}$ content in the atmosphere. Although it was shown that $\mathrm{Hg}$ emission during fuels combustion by cars is relatively low if compared to other sources of this pollutant, it should be mentioned that long-range atmospheric transport can be also important factor increasing air pollution by $\mathrm{Hg}$. Another $\mathrm{Hg}$ point sources connected with energy production are batteries, fluorescent lamps, wiring devices or electrical switches, which together with various measuring and control instruments cause the rise of the $\mathrm{Hg}$ emissions into environment. The intensifying use of energy since the Industrial Revolution has increased the $\mathrm{Hg}$ content in the air, water and soil. In 1990 global $\mathrm{Hg}$ emission was about $1800 \mathrm{t}$, in 1995 it was more than 2200 and in 2005 some results shown value close to 3000 t. Additionally, in 2005 it

\footnotetext{
a Corresponding author: dariusz.latowski@uj.edu.pl
} 
was postulated that more than $60 \%$ of the global mercury emission were generated by energy production [5]. The level of $\mathrm{Hg}$ emission varies greatly dependently on continent or even country [6]. If controls of $\mathrm{Hg}$ emission to environment will not be extended worldwide, the rise of the mercury emission is predicted. In the environment, mercury can exist in the form of molten metal, mercury bound in natural minerals, vaporous mercury in the atmosphere $(\mathrm{HgO})$, as well as in the form of ions particularly in water and soil. Most of $\mathrm{Hg}$ forms are highly toxic even at low concentrations, particularly for fetuses and children [7, 8]. Even though detection of $\mathrm{Hg}$ emission in 2013 was about $1000 \mathrm{t}$ lower than in 2005, mercury still seriously threatens life on our planet and as a strong pollutant can exist in the air more than 350 years. It was also shown that $\mathrm{Hg}$ in soils is much more persistent than in fresh or sea water ecosystems or even in biomes [1]. What is worse, mercury can relocate among long distances through different ecosystems and can easily penetrate various components of biosphere. In this way, mercury mainly from water and soil, entering to food chains strongly degrades ecosystems and finally seriously endangers to humans health [9]. Accordingly, it is urgent need for rapid introduction of methods for efficient removal $\mathrm{Hg}$ from the environment components or to transform it into its most stable and less toxic forms in situ $[10,11]$. Among numerous remediation techniques applying to neutralize of $\mathrm{Hg}$ contamination in environment $[12,13]$ one of the most promising method is bioremediation with mercury tolerant microorganisms. In this paper screening, identification and characteristics of six new high mercury concentration resistant Pseudomonas strains will be presented.

\section{Materials and methods}

\subsection{Soil sampling}

Five soil samples were collected from the top layer of the ground of $10 \mathrm{~cm}$ depth on mercury contaminated area of the abandoned electrolysis factory. The area was not remediated after cessation of the factory activity in 2006. The sampling points intervals were regular and about $50 \mathrm{~m}$. The original samples were then homogenized to prepare the representative laboratory sample. The concentration of mercury in the soil sample was determined by cold vapour atomic absorption spectrometry (CVAAS).

\subsection{Microorganisms isolation}

$3 \mathrm{~g}$ of representative soil sample was suspended in $75 \mathrm{ml}$ of sterile $0.9 \% \mathrm{NaCl}$ solution and shaken for $48 \mathrm{~h}\left(150 \mathrm{rpm}, 20^{\circ} \mathrm{C}\right) .300 \mu \mathrm{l}$ of the extract was inoculated to agar plates with Luria Bertani broth medium (LB) $(\mathrm{NaCl} 10 \mathrm{~g} / \mathrm{L}$; peptone $10 \mathrm{~g} / \mathrm{L}$; yeast extract $5 \mathrm{~g} / \mathrm{L}$ ) supplemented with $\mathrm{HgCl}_{2}$ to reach the final pure mercury concentration:
$0.03 ; 0.50 ; 1.00$ and $1.50 \%(\mathrm{w} / \mathrm{v})$ in the first step and $0.001 ; 0.002 ; 0.004 ; 0.008 ; 0.015 ; 0.020$; $0.025 \%(\mathrm{w} / \mathrm{v})$ in the second step of the experiment. Medium without $\mathrm{Hg}$ was used as a control. The plates were incubated for $48 \mathrm{~h}, 20^{\circ} \mathrm{C}$. The colonies grown on medium with highest concentration of $\mathrm{Hg}$ were seeded on streaking plates with LB supplemented with $\mathrm{Hg}$. Single colonies distinguished basing on morphology were inoculated to liquid LB and incubated with shaking $\left(150 \mathrm{rpm}, 20^{\circ} \mathrm{C}\right) 4$ days, and then streaking plates were prepared. The procedure was repeated 4 times and resulted in obtaining pure strains. Isolated strains were stored on LB supplemented with $0.01 \%(\mathrm{w} / \mathrm{v}) \mathrm{Hg}$ agar plates and liquid cultures were stored with $70 \%$ glycerol solution (4:1) under $-80^{\circ} \mathrm{C}$. Six selected pure strains were stained by Gram staining and analyzed by microscope (Nikon Eclipse TE200 Inverted Fluorescence \& Brightfield Microscope).

\subsection{Bacteria identification}

DNA was extracted from selected six 4-days liquid LB cultures supplemented with $0.01 \% \mathrm{Hg}$, marked $12.4,15.5,16.2,16.7,17.1$ and 17.5 according to phenol-chloroform extraction method. The concentration of the extracted material was measured at $260 \mathrm{~nm}$ wavelength. The purity of isolated DNA was estimated as a $260 \mathrm{~nm} / 280 \mathrm{~nm}$ measurements ratio together with its concentration by a nano-drop spectrophotometer (Implen NanoDrop). DNA was amplified with PCR on thermal cycler (Bio-Rad S1000т Thermal Cycler) with standard $8 \mathrm{~F}$ (5'-AGAGTTTGATCCTGGCTCAG-3') and 1492R (3'-GGTTACCTTGTTACGACTT-5') primers under following conditions: $95^{\circ} \mathrm{C}$, initial denaturation, $15 \mathrm{~min} ; 95^{\circ} \mathrm{C}$ subsequent denaturation, $1 \mathrm{~min}$; annealing, $54^{\circ} \mathrm{C}, 1 \mathrm{~min}$; elongation $72^{\circ} \mathrm{C}$, $2 \mathrm{~min}$; repeated 30 times; $72^{\circ} \mathrm{C}$ final elongation, $10 \mathrm{~min}$. The PCR product was subjected to ethidium-bromide agarose gel electrophore sis separation (20 min, $80 \mathrm{~V}$ ) and purified with SynGen GEL/PCR Mini Kit according to the attached protocol. The isolated, amplified and purified DNA samples of 6 selected strains were sequenced. The data set were aligned using Chromas Lite Version 2.1.1 and BioEdit 7.2.5 and identified basing on V-4 hypervariable region with BLAST database, determining the genus and species by the highest similarity.

\subsection{Growth kinetics dependence on $\mathrm{Hg}$ concentration}

4-days liquid $\mathrm{LB}$ without $\mathrm{Hg}$ cultures of six selected isolates were inoculated to $15 \mathrm{ml}$ of liquid LB medium supplemented with different concentrations $(\% \mathrm{w} / \mathrm{v})$ of mercury: $0.002,0.005,0.01$ and without $\mathrm{Hg}$ (control) to obtain initial optical density (OD) at $600 \mathrm{~nm}$ between $0.01-0.08$. The cultures were incubated with shaking $(200 \mathrm{rpm})$ in $37^{\circ} \mathrm{C}$. 
The growth kinetics was measured by OD measurements at $600 \mathrm{~nm}$ wavelength $\left(\mathrm{OD}_{600}\right)$ using Metertek SP-830 Spectrophotometer every 2 hours till cultures reached initial stage of death phase after 45 hours on average.

\subsection{Growth kinetics dependence on $\mathrm{pH}$}

4-days old cultures in liquid LB supplemented with $0.01(\% \mathrm{w} / \mathrm{v}) \mathrm{Hg}$ were inoculated to $15 \mathrm{ml}$ of LB medium solved in ammonium acetate-acetic acid buffer of $\mathrm{pH} 3,5,6,7$ and 8 supplemented with $0.01 \%(\mathrm{w} / \mathrm{v})$ of $\mathrm{Hg}$ and of $\mathrm{pH} 3,5,6,7$ and 8 without $\mathrm{Hg}$. The initial $\mathrm{OD}_{600}$ value was in the range of $0.01-0.02$. The cultures were inoculated in triplicate. The $\mathrm{OD}_{600}$ measurements were carried on every 4 hours till cultures reached initial stage of death phase, i.e. after $50 \mathrm{~h}$ on average. The $\mathrm{pH}$ influence on growth kinetics was presented as specific growth rate of bacteria culture ( $\mu$ ) calculated according to following equation:

$$
\mu=\Delta \ln O D_{600} / \Delta t
$$

where $t$ is time (hours).

\subsection{Mercury removal by the bacterial isolates}

Samples to determine the mercury removal by isolated strains were prepared as follows: the 4-days liquid $\mathrm{LB}$ cultures without $\mathrm{Hg}$ were inoculated to $20 \mathrm{ml}$ of LB $0.01 \%(\mathrm{w} / \mathrm{v}) \mathrm{Hg}$ medium and cultured with shaking $(200 \mathrm{rpm})$ in $37^{\circ} \mathrm{C}$. The cultures were prepared in triplicate and the initial $\mathrm{OD}_{600}$ values were between 0.01-0.08. $10 \mathrm{ml}$ of cultures were collected for analyses of $\mathrm{Hg}$ concentration after 12 and $120 \mathrm{~h}$. The samples were centrifuged $(5500 \mathrm{rpm}, 20 \mathrm{~min}$, $4^{\circ} \mathrm{C}$ ). Supernatant was collected and stored under $-20^{\circ} \mathrm{C}$ before analysis. An Automated Mercury Analyzer MA-2000 (Nippon Instruments Corporation) was used for total mercury determination in examined samples. The method is based on the thermal release of mercury vapours $\left(\mathrm{Hg}^{0}\right)$ from solid or liquid materials and capturing it through the amalgamation process. After the thermal release of atomic mercury vapours from the amalgam, the atomic absorption measurement was performed in the measurement vessel at the wave length of $253.7 \mathrm{~nm}$ (measuring the range $0-1000 \mathrm{ng} / \mathrm{sample}$, limit of detection LOD-0.002 ng). The samples were combusted at $850^{\circ} \mathrm{C}$ in filtered dry air. The main advantage of used method is its ability to process samples without conducting sample mineralization. The correctness of the measurements was verified by means of standard reference material.

\section{Results}

\subsection{Isolation and identification of microorganisms}

The analysis of contaminated soil samples, the source of isolated bacteria performed by cold vapour atomic absorption spectrometry demonstrated that the content of mercury is $153 \pm 23 \mathrm{mg} / \mathrm{kg}$ d.m. $(1.5 \% \quad \mathrm{w} / \mathrm{w})$. The result of this analysis was the basis for selection of mercury concentrations to isolate bacteria possessing the strongest resistance to this pollutant.

At the first stage of the experiment the highest concentration of the mercury in selective medium was similar to the concentration in collected soil and was $1.5 \%(\mathrm{w} / \mathrm{v})$ and the lowest one was $0.03 \%$ (see part 2.2). Despite of bacteria growth on the control plates (not supplemented with $\mathrm{Hg}$ ) there were no observed any bacterial colonies on $\mathrm{Hg}$ containing media. Therefore in the next stage of bacteria isolation the concentrations were reduced to the range $0.001-0.25 \%(\mathrm{w} / \mathrm{v})$ (see part 2.2). Under provided conditions the bacteria cells grew on every selected concentrations, but after several passages they lost capability of growth when treated with concentrations of $\mathrm{Hg}$ higher than $0.015 \%(\mathrm{w} / \mathrm{v})$

The result of applied procedures was obtaining of 54 pure bacterial cultures differing with morphology and type of growth on LB-agar medium. Six strains showing the most visible morphological differences and resistance to highest content of mercury in medium were selected to research. Gram staining and microscope analysis demonstrated, that all selected isolates belong to Gram negative bacteria and demonstrate features characteristic for Pseudomonas genus. The identification of all isolated strains by V-4 hypervariable region highest similarity comparing to GenBank data determined the genus as Pseudomonas ( $P$. syringae, access no NC_005773.3, GenBank), despite the morphological differences observed for particular cultures. Isolates were marked by following numbers: $12.4,15.5,16.2,16.7,17.1$, 17.5.

\subsection{Growth kinetics in presence of $\mathrm{Hg}$}

The characterized Pseudomonas strains cultured in medium without $\mathrm{Hg}$ did not demonstrate significant differences in growth kinetics (Fig. 1A). The increase of mercury concentration in the medium effected in differentiation of cells growth, the more significant, the higher concentration of $\mathrm{Hg}$ (Fig. 1B-D).

The first difference observed just at the lowest concentration of $0.02 \%$ was that the strains 16.7 and 17.5 demonstrate the fastest growth, but probably 16.7 initiates cells division earlier in comparison to 17.5 under given conditions. 3 hours after inoculation there was visible enlargement of 16.7 strain population, whereas all other strains show similar increase from 5th hour of incubation and the more decelerated, the higher concentration of $\mathrm{Hg}$ in the medium is. There was also observed, that the kinetics of $12.4,15.5,16.2$ and 17.1 growth are similar, which is clearly visible especially in cultures supplemented with $0.005 \%$ 
(w/v) of $\mathrm{Hg}$ (Fig. 1C). In case of cultures supplemented with $0.01 \%(\mathrm{w} / \mathrm{v})$ of $\mathrm{Hg}$ the diversity of growth is the most visible and allows to put the strains according to the growth rate in a following order, correlated with the decreasing resistance to mercury: $16.7>>15.5=17.5>16.2=17.1>12.4$ (Fig. 1D).

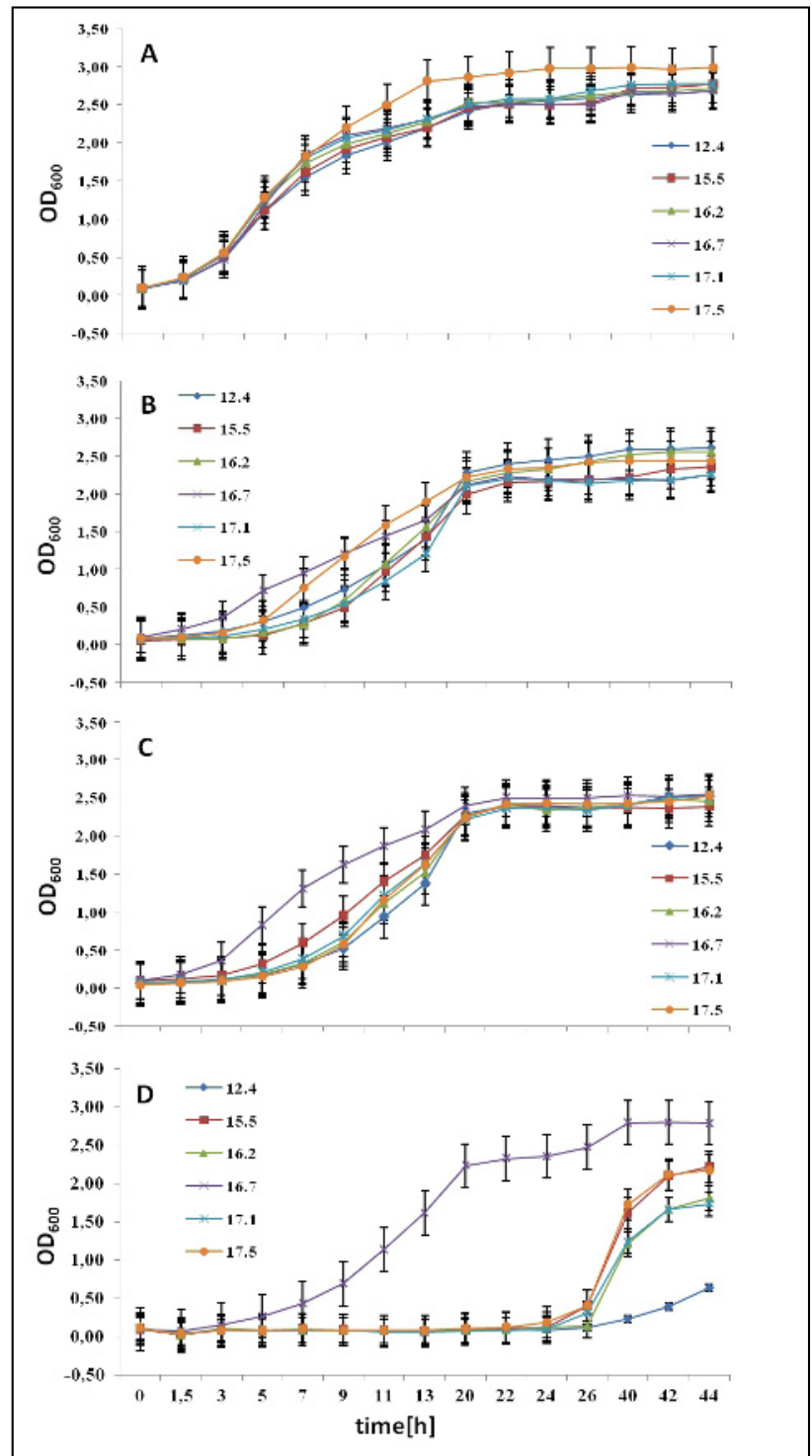

Figure 1. Growth kinetics of isolated bacteria strains without $\mathrm{Hg}(\mathrm{A})$ and $0.002 \%(\mathrm{~B}), 0.005 \%$ (C) and $0.01 \%$ (D) (w/v) Hg.

\subsection{Mercury removal}

The capability of mercury removal by investigated strains was analyzed after 12 and 120 hours of incubation (Tab.1). After $12 \mathrm{~h}$ there are no observed differences of mercury content in the medium, whereas after $120 \mathrm{~h}$ the removal of $\mathrm{Hg}$ was over $99 \%$ in case of strains $15.5,16.7$, 17.1 and 16.2. The order of bacterial growth rate is related to the level of mercury removal from medium, which is the higher, the faster growth demonstrate studied Pseudomonas strains. Only 17.5 strain growing as well as 15.5 strain has shown the lowest removal of mercury from medium.
It was even lower than 12.4 strain characterized by weaker growth of the culture.

Table 1. Mercury removal by isolated strains. Initial concentration of $\mathrm{Hg}$ was $0.01 \%$ (w/v)

\begin{tabular}{|c|c|c|}
\hline \multirow{2}{*}{ Strain } & \multicolumn{2}{|c|}{ Time $[\mathbf{h}]$} \\
\cline { 2 - 3 } & $\mathbf{1 2}$ & $\mathbf{1 2 0}$ \\
\hline 12.4 & 0.0016 & 0.000150 \\
\hline 15.5 & 0.0022 & 0.000049 \\
\hline 16.2 & 0.0020 & 0.000089 \\
\hline 16.7 & 0.0018 & 0.000050 \\
\hline 17.1 & 0.0021 & 0.000057 \\
\hline 17.5 & 0.0024 & 0.000200 \\
\hline
\end{tabular}

\subsection{Effect of pH on bacteria growth}

In $\mathrm{pH} 3.0$ and $\mathrm{pH} 5.0$ no growth of investigated strain cultures either in medium supplemented with mercury or without presence of this element was observed. There were also no significant differences of growth kinetics dependent on $\mathrm{pH}$ among selected strains (Tab. 2).

Table 2. The effect of different $\mathrm{pH}$ values on specific growth rate $(\mu)$ of selected strains treated and untreated with $\mathrm{Hg}$

\begin{tabular}{|c|c|c|c|}
\hline \multirow{2}{*}{$\begin{array}{c}\text { Strain } \\
\text { No }\end{array}$} & \multicolumn{3}{|c|}{ Control (without $\mathrm{Hg}$ ) $\left[\mathrm{x10}^{-3} / \mathrm{h}\right]$} \\
\hline & pH 6.0 & pH 7.0 & pH 8.0 \\
\hline 12.4 & $10.00 \pm 0.61$ & $43.89 \pm 0.51$ & $43.83 \pm 0.60$ \\
\hline 15.5 & $11.00 \pm 0.41$ & $43.92 \pm 0.21$ & $43.97 \pm 0.45$ \\
\hline 16.2 & $10.52 \pm 0.47$ & $43.87 \pm 0.45$ & $43.85 \pm 0.55$ \\
\hline 16.7 & $11.06 \pm 0.51$ & $43.91 \pm 0.54$ & $43.99 \pm 0.51$ \\
\hline 17.1 & $11.03 \pm 0.47$ & $43.85 \pm 0.39$ & $43.88 \pm 0.45$ \\
\hline 17.5 & $10.50 \pm 0.51$ & $43.89 \pm 0.45$ & $43.85 \pm 0.53$ \\
\hline Strain & \multicolumn{3}{|c|}{ With $0.01 \%(w / v) ~ H g\left[\times 10^{-3} / h\right]$} \\
\hline No & pH 6.0 & pH 7.0 & pH 8.0 \\
\hline 12.4 & $4.20 \pm 0.05$ & $19.10 \pm 0.50$ & $19.18 \pm 0.45$ \\
\hline 15.5 & $5.11 \pm 0.04$ & $21.78 \pm 0.51$ & $22.21 \pm 0.53$ \\
\hline 16.2 & $4.60 \pm 0.06$ & $21.24 \pm 0.45$ & $20.99 \pm 0.47$ \\
\hline 16.7 & $5.11 \pm 0.05$ & $24.21 \pm 0.47$ & $25.01 \pm 0.53$ \\
\hline 17.1 & $5.02 \pm 0.05$ & $21.45 \pm 0.55$ & $21.65 \pm 0.39$ \\
\hline 17.5 & $4.91 \pm 0.03$ & $21.59 \pm 0.35$ & $22.12 \pm 0.45$ \\
\hline
\end{tabular}

The optimum $\mathrm{pH}$ values for all strains were $\mathrm{pH}$ 7.0 and $\mathrm{pH} 8.0$, in which the bacterial growth was about $80 \%$ more efficient than at $\mathrm{pH}$ 6.0. In presence of $\mathrm{Hg}$ the specific growth rate $(\mu)$ of particular strains was almost two times lower than without $\mathrm{Hg}$, but the ratio of $\mu$ in case of buffered $\mathrm{pH} 7.0$ and nonbuffered LB medium was close to 1 . This result indicates, that the growth-limiting factor is the presence of toxic metal, not the $\mathrm{pH}$ value. The higher $\mathrm{pH}$ values have not been tested, as the $\mathrm{Hg}$ compound precipitated in more alkaline conditions.

\section{Discussion}

Performed experiments resulted with isolation and preliminary characteristics of mercury resistant Pseudomonas strains. The source of bacteria was soil contaminated with high concentration of $\mathrm{Hg}$ 
$(1.5 \% \quad \mathrm{w} / \mathrm{w})$. Under laboratory conditions this concentration occurred to be extremely toxic for selected microorganisms to adapt. During the progress of isolation procedure the highest concentration of $\mathrm{Hg}$ permanently tolerated by the most resistant bacteria was 0.015 , which was 100 times lower than in soil. Admittedly, at the beginning bacteria growth was observed on media with $0.025 \% \mathrm{Hg}(\mathrm{w} / \mathrm{v})$ but in successive passage no growth of these strains was observed. One of the putative reason for this result is fact that the chemical and biological composition of the soil provide another conditions than laboratory medium. Mineral compounds as well as edaphon may decrease the bioavailability of $\mathrm{Hg}$ present in the soil. It is also possible that the provided laboratory conditions of culturing were not optimal for investigated strains. The other explanation is that separation of single strains functioning in soil as a consortium so far, resulted with increase of sensitivity to $\mathrm{Hg}$. It is possible that in natural environment they derive benefits from interrelationships $[14,15]$, what will be researched in future experiments.

The analysis of growth kinetics of selected strains cultured with different mercury concentrations demonstrated that one strain (16.7) possesses more efficient mechanisms of resistance in comparison to the another isolates (Fig. 1A-D). It is reported several mercury resistance mechanisms such as methylation of mercury [16-18], involving methylation proceeded by bacteria excreting methylcobalamin [17], $\mathrm{Hg}^{2+}$ to $\mathrm{Hg}^{0}$ reduction by reductase encoded by mer operon possessed by numerous bacterial strains [19-24], presence of plasmids providing resistance to another heavy metals, correlated with antibiotics resistance [17], precipitation in form of $\mathrm{HgS}$ [25] and the synthesis of thiols or another chelates binding the $\mathrm{Hg}$ compounds $[17,26]$. All of these mechanisms work efficiently and decrease mercury toxicity to the cells.

While analysis of the effect of $\mathrm{Hg}$ concentration on the growth kinetics of particular strains it was noted, that even in case of the highest concentration of mercury, i.e. $0.01 \% \quad(\mathrm{w} / \mathrm{v})$, there are no differences between strains 15.5 and 17.5 as well as 16.2 and 17.1 (Fig. 1D). Basing on that observation it may be concluded, that they are the same strain, but on the other hand when consider the $\mathrm{Hg}$ removal from the medium after 120 hours of incubation, in case of 15.5 the content of $\mathrm{Hg}$ was more reduced than in case of 17.5 , which removed $\mathrm{Hg}$ less efficiently even than strain 12.4 presenting the weakest growth. For unmistakable explanation if selected bacteria are the same or different strains further studies on $\mathrm{Hg}$ resistance molecular mechanism are needed. One of the possible mechanisms may be mercuric reductase activity. The $\mathrm{pH}$ optimum for activity of the enzyme is 8 [27], what corresponds with $\mathrm{pH}$ value favourable for bacteria growth, which was observed while incubation of investigated isolates (Tab. 2). However, the optimal $\mathrm{pH}$ is the same ( $\mathrm{pH}$ 8.0) for cultures independently if they are treated or untreated with mercury. Therefore it cannot be concluded that the most efficient cells growth at $\mathrm{pH} 8.0$ is a consequence of mercuric reductase detoxification activity.

The selected strains characterizes strong resistance to high concentrations of mercury and by their activity contribute to $\mathrm{Hg}$ removal from the solution (Tab. 1). The results and conclusions of carried experiments are promising for use of $P$. syringae in bioremediation of areas contaminated with mercury. The next stage of research in this field is to investigate all 54 isolated strains and exploring the mechanism of their resistance to mercury, focusing on utility for neutralization the harmful effect of $\mathrm{Hg}$ on environment.

\section{References}

1. J. Xu, A.G. Bravo, A. Lagerkvist, S. Bertilsson, R. Sjöblomb, J. Kumpiene, Environ. Int. 74 (2015)

2. U.C. Branch, The global atmospheric mercury assessment: sources, emissions and transport (Geneva: UNEP-Chemicals, 2008)

3. E.G. Pacyna, J.M. Pacyna, K. Sundseth, J. Munthe, K. Kindbom, S. Wilson, F. Steenhuisen, P. Maxson, Atmos. Environ. 44, 20 (2010)

4. N. Pirrone, S. Cinnirella, X. Feng, R.B. Finkelman, H.R. Friedli, J. Leaner, R. Mason, A.B. Mukherjee,G.B. Stracher, D.G. Streets, K. Telmer,Atmos. Chem. Phys. 10 (2010)

5. E.G. Pacyna, J.M. Pacyna, F. Steenhuisen, S. Wilson, Atmos. Environ. 40 (2006)

6. P. Holmes Sci. Tota.1 Environ. 408, 2 (2009)

7. P. Nance, J. Patterson, A. Willis, N. Foronda, M. Dourson Regul. Toxicol. Pharmacol. 62, 3 (2012)

8. M. Gabriel, Environ. Geochem. Hlth. 26, 3-4 (2004)

9. W.W. Cui, X.L. Wang, J.J. Duan, M . Yang, W. Zi, X.C. Liu, Guizhou. Agric. Sci. 7 (2011)

10. B.V. Tangahu, Sheikh S.R. Abdullah, H. Basri, M. Idris, A.N. M. Mukhlisin, Int. J. Chem. Eng. 2011 (2011)

11. P. Randall, S. Chattopadhyay, J. Hazard Mater. 114, 1 (2004)

12. R.B. Richter, H. Flachberger, BHM 155, 12 (2010)

13. O. Rodríguez, I. Padilla, H. Tayibi, A. LópezDelgado, J. Environ. Manag. 101 (2012)

14. M. Ledin, Earth Sci. Rev. 51 (2000)

15. A.R. Sprocati, C. Alisi, L. Segre, F. Tasso, M. Galletti, C. Cremisini, Sci. Total Environ. 366, 2-3 (2006)

16. M. Pepi, C. Gaggi, E. Bernardini, S. Focardi, A. Lobianco, M. Ruta, V. Nicolardi, M. Volterrani, S. Gasperini, G. Trinchera, P. Renzi, M. Gabellini, S. E. Focardi, Int. Biodeter. Biodegr. 65, 1 (2011)

17. J.B. Robinson, O. H. Tuovinen, Microbiol. Revs. 48, 2 (1984)

18. N. S. Reyes, M. E. Frischer, P. A. Sobecky, FEMS Microbiol. Ecol. 30 (1999)

19. D.H. Nies Appl Microbiol Biotechnol 51 (1999) 
20. T. Barkay, S.M. Miller, A. Summers, FEMS Microbiol. Rev. 27 (2003)

21. T. Barkay, I. Wagner-Döbler, Adv. Appl. Microbiol. 57 (2005)

22. A.O. Summers, J. Bacteriol. 174 (1992)

23. M. Narita, K. Chiba, H. Nishizawa, H. Jshij, C.C. Huang, Z. Kawabata, S. Silver, G. Endo, FEMS Microbiol. Lett. 223 (2003)

24. S. Silver, J.L. Hobman, Microbiol. Monographs. 6 (2007)

25. D.W. Boening, Chemosphere 40 (2000)

26. S. Silver, L.T. Phung, J. Ind. Microbiol. Biotechnol. 32 (2006)

27. P. Giovanella, L. Cabral, F.M. Bento, C. Gianello, F.A.O. Camargo, New Biotechnol. 33, 1 (2016) 